\title{
Road Traffic Accident Deaths in Benghazi during (2011)
}

\author{
Samir Elmrghni*, Mahmud Kaddura \\ Department of Forensic Medicine and Toxicology- Faculty of Medicine- University of Benghazi-Libya \\ *Corresponding Author: Samir Elmrghni, Department of Forensic Medicine and Toxicology- Faculty of \\ Medicine-University of Benghazi-Libya, Email: Samir3272@yahoo.ie
}

\begin{abstract}
This work aims to observe and to study the figures of road traffic accidents (RTA's) as a cause of death during (2011) in Benghazi City. Analysis was done using the patient records of Al-Jalaa hospital (the main trauma centred in Benghazi) from over 200 RTA cases received at that time, was to observe if RTA still considered as a major unnatural cause of death among young Libyans regarding previous statistics or it is affected by other traumatic causes of death through 2011.The data were compared to each other and changes of trends were observed. We conclude that an RTA death at that year was still high when compared with other causes of death.
\end{abstract}

Keywords: Benghazi, RTA, deaths

\section{INTRODUCTION}

The road traffic injuries take a greater task on human life every day on our roads. A large number of people from all walks of life and of all age groups become victims of this catastrophe and never return home, leaving behind their families shattered communities. Over 1.27 million people lose their lives and 20 and 50 million are injured each year on the world's roads. 1,2 the road traffic mortality rates in low and middle income countries (21.5 and 19.5 per 100000 population, respectively) are twice than that in high-income countries (10.3 per 100 000). (2)

No age group is immune from the road traffic injuries, but the most vulnerable victims are the younger people between 5 and 44 years of age, in whom they are consistently one of the top three causes of mortality. (1) Although many developed countries have shown static or decreased road traffic mortality rates in recent decades, the absolute fatality and casualty figures are rising rapidly in the majority of developing countries. It has been estimated that without immediate effective intervention, RTA will become the fifth leading cause of death by 2030 resulting in an estimated 2.4 million fatalities annually. (3) In Libya, accidents cost the country about $\$ 160$ million in 1978.

In the UK External causes of death (4), which tends to be less disease and medical focused, accounted for $3.8 \%$ of all fatalities in 2009 .
Road traffic accidents make up $13 \%$ of all external causes of death. For the 10-14 age group's road accidents make up over $50 \%$ of all external causes of death.

15-19 years olds experience almost double the risk of death from road traffic accidents (82.5 deaths per million populations) in comparison to the general population ( 42.2 deaths per million populations). For males in this age group the risk is higher still at 127.3 deaths per million populations.

There is also a significant and notable disparity between the deaths caused by road traffic accidents between men and women, with men being over three times as likely to die from a road accident.

Deaths from road traffic accidents are much more prevalent amongst the under $25 \mathrm{~s}$ than other causes of death often reported by the media such as hangings, shootings, stabbings, alcohol or drug abuse. Between the ages of 1524 a young person is twice as likely to die from a road traffic accident as be fatally assaulted by firearms, a sharp/blunt object or intentional selfharm via hanging combined. Those in the 15-24 age categories are also four times more likely to die from a road traffic accident than from drug, alcohol or other substance poisoning.

\section{OBJECTIVE}

The present study was conducted to analyze the demographic and mortality profile of RTA during (2011), thereby creating public 
awareness in order to develop and implement multispectral strategy for their prevention /control.

\section{MAterial AND MethodS}

This study was conducted on 200 RTA cases brought to AL- Jalaa Hospital during (2011).
The data sources were from statistical files of those victims

Data thus collected and compared with other traumatic causes of deaths and then figured and statistically analyzed on SPSS.

\section{RESUlts}

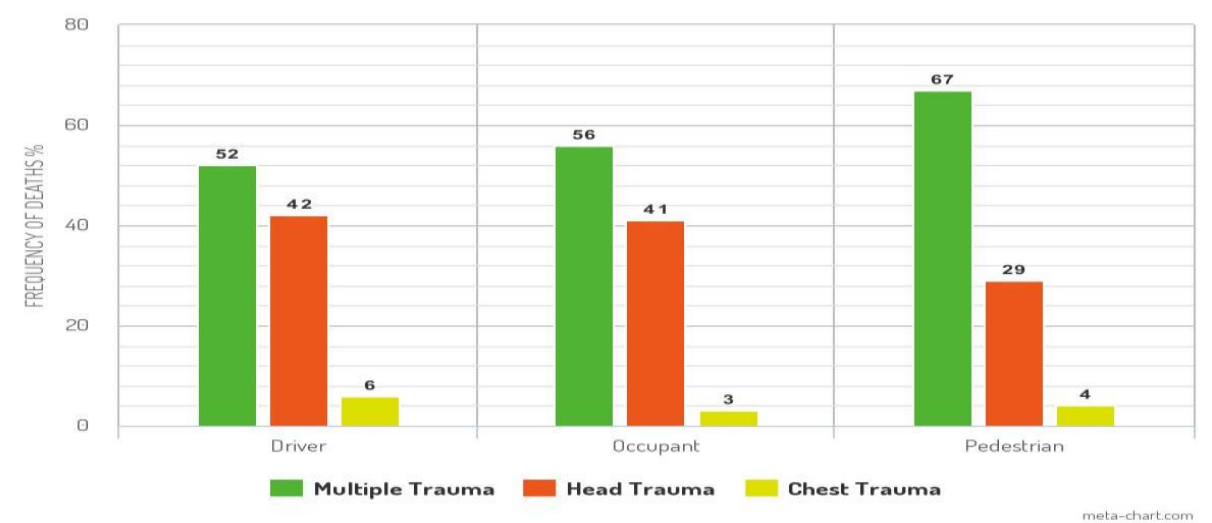

Figure1: Common causes of deaths among victims of RTAs

\section{Data Analysis}

Road traffic injuries account for $2.1 \%$ of global mortality. The developing countries bear a large share of burden and account for about $85 \%$ of the deaths as a result of road traffic crashes (5). So, the problem of road traffic accidents is becoming recognized concern. The World Health Organization has predicted that traffic fatalities will be the sixth leading cause of death worldwide and the second leading cause of disability-adjusted life-years lost in developing countries by the year $2020(6,7)$.

There is a clear and visible increase in the number of motor vehicle collisions in Benghazi $(8,9)$ and proportionately more people are taken to Al-Jalaa as a result of car accidents. In 2011 there were just over 200 deaths in Benghazi city. The largest proportion of deaths is attributable to external causes, of which transport accidents plays a part.

When all causes of death are analysed further by age and gender it is possible to see that there are some marked differences between the causes of death particularly at different life stages (fig4), Road traffic accidents account for $32.9 \%$ of all deaths (Figure 2), they amount to $85 \%$ of the deaths in the 26-35 age group (Figures 4 and 6). Overall men are over three times as likely to die from a road accident in comparison to women.

From figures 2 and 6 it is clear to see that although other underlying causes such as falls and other accidental injury make up a less part of all external injuries before this point road accident deaths are the highest cause of death amongst the young, particularly the under $35 \mathrm{~s}$ fig-4. From figures 3 and 7 we can observe that the most common cause of death among RTA victims was multiple trauma then head trauma and the largest death number was among occupants (Front and rear seats) $42 \%$ then drivers 37.

The most common second traumatic cause of death was gunshot deaths amongst 26-35 age groups fig5

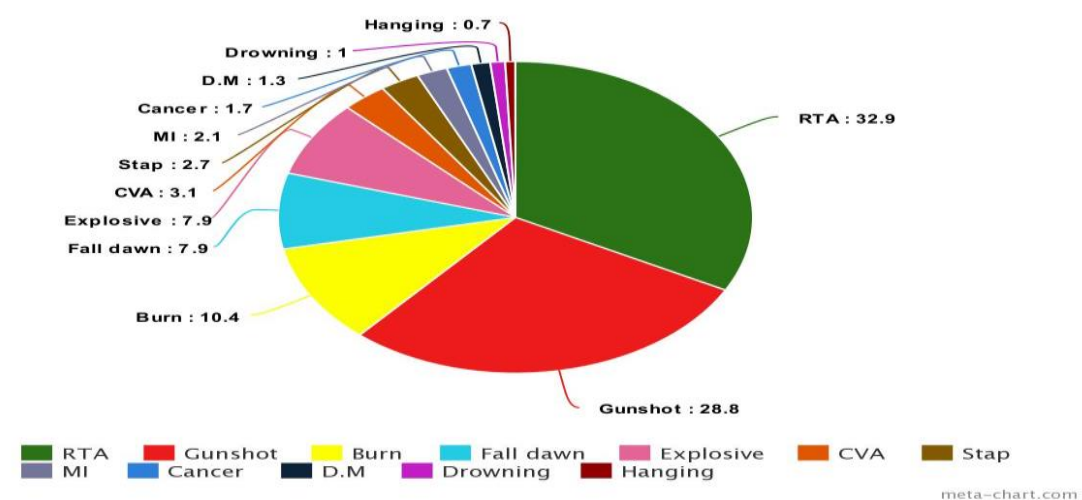

Figure2: Percentage of other causes of deaths during 2011 compared with 200 cases of RTA 


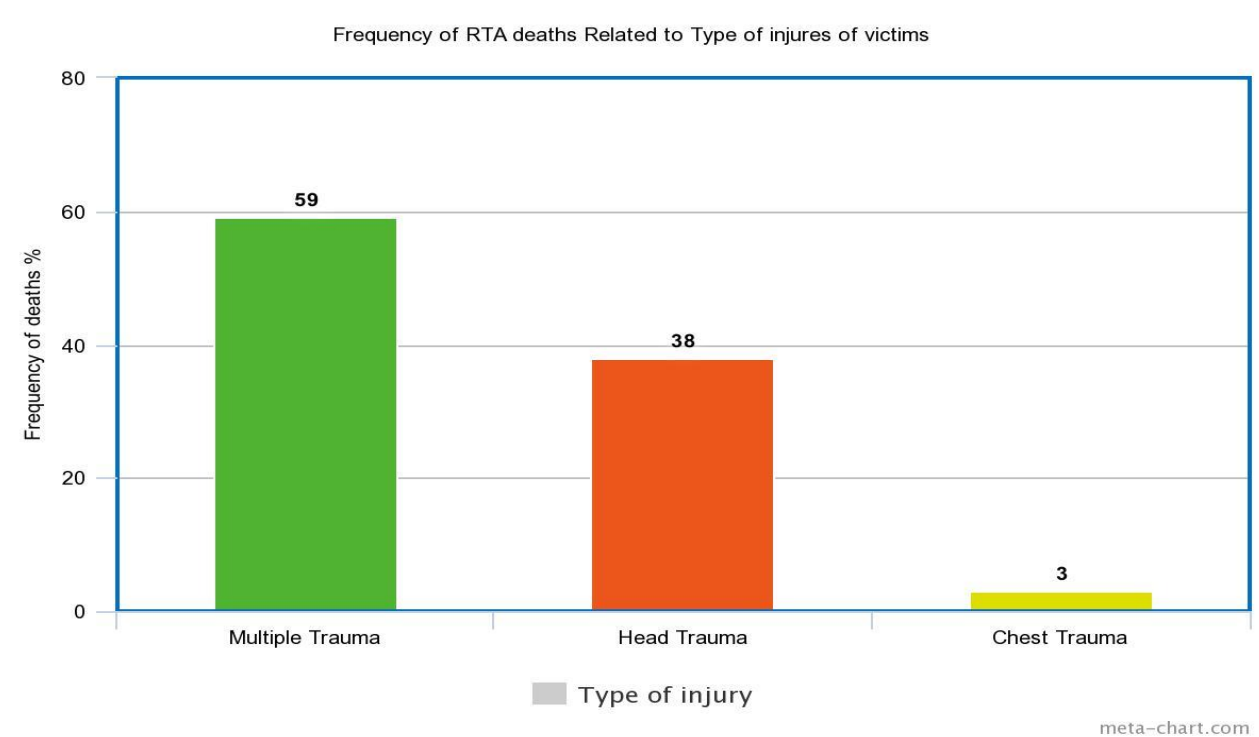

Figure3: Common causes of RTA deaths as certified at that time

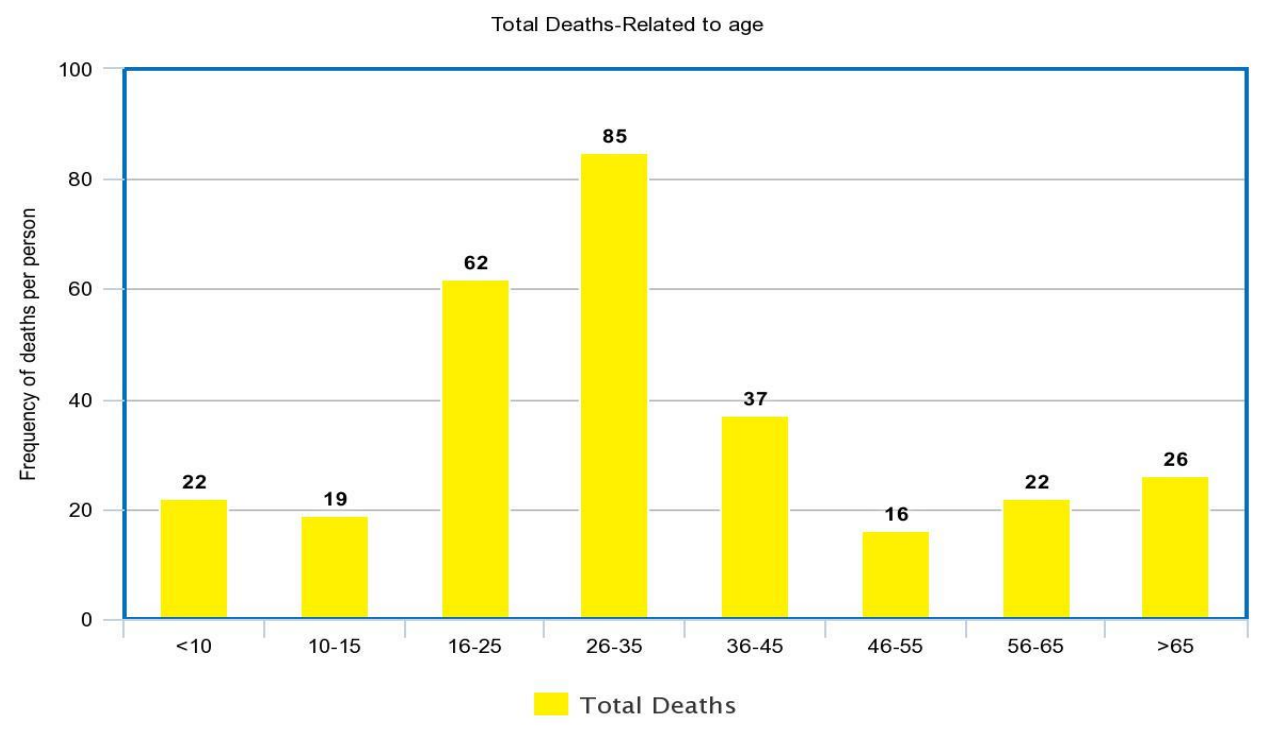

Figure4: Percentages of RTA deaths related to age groups

Total gunshot Deaths-Related to age

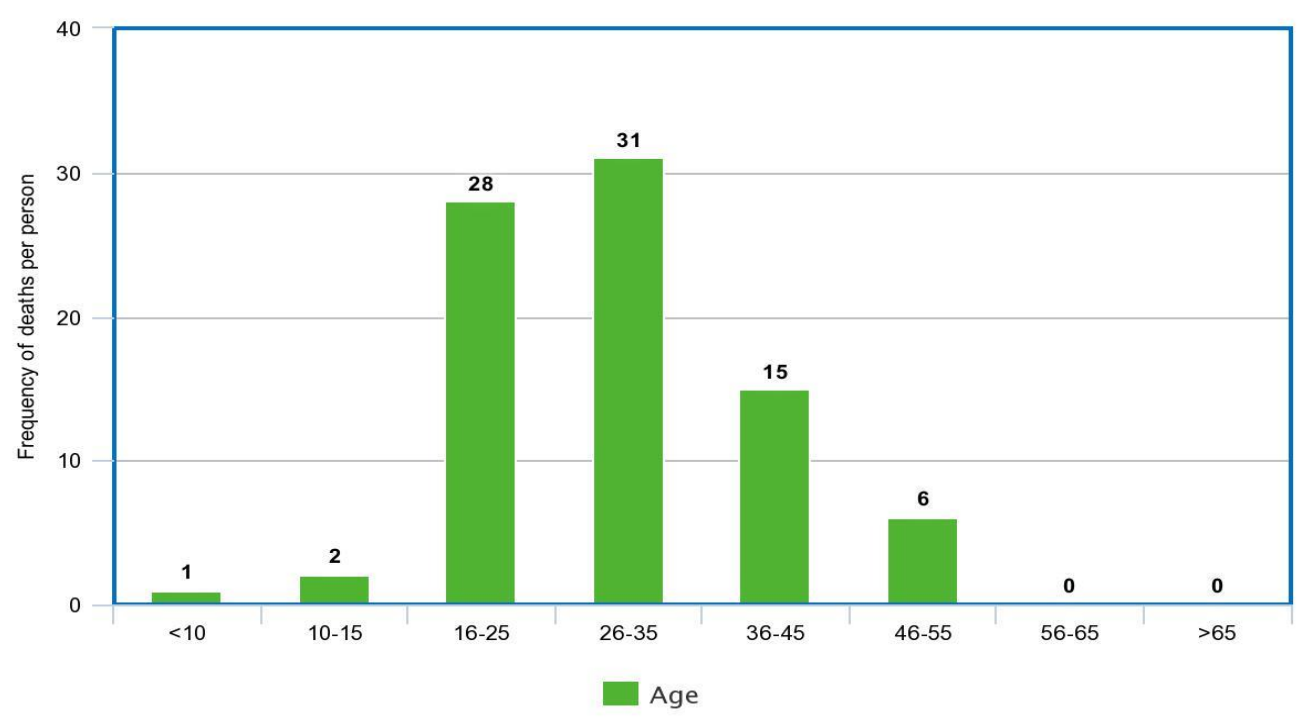

Figure5: Total gunshot deaths related to different age groups 


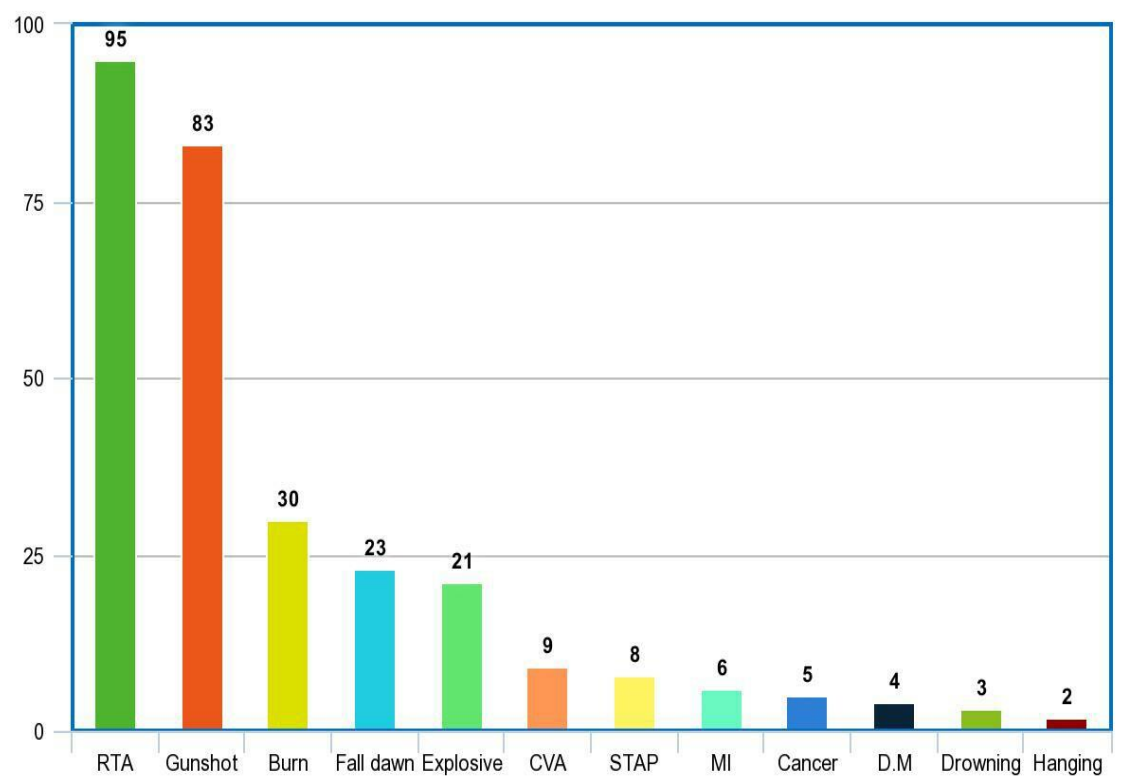

Figure6: Common causes of unnatural deaths through 2011

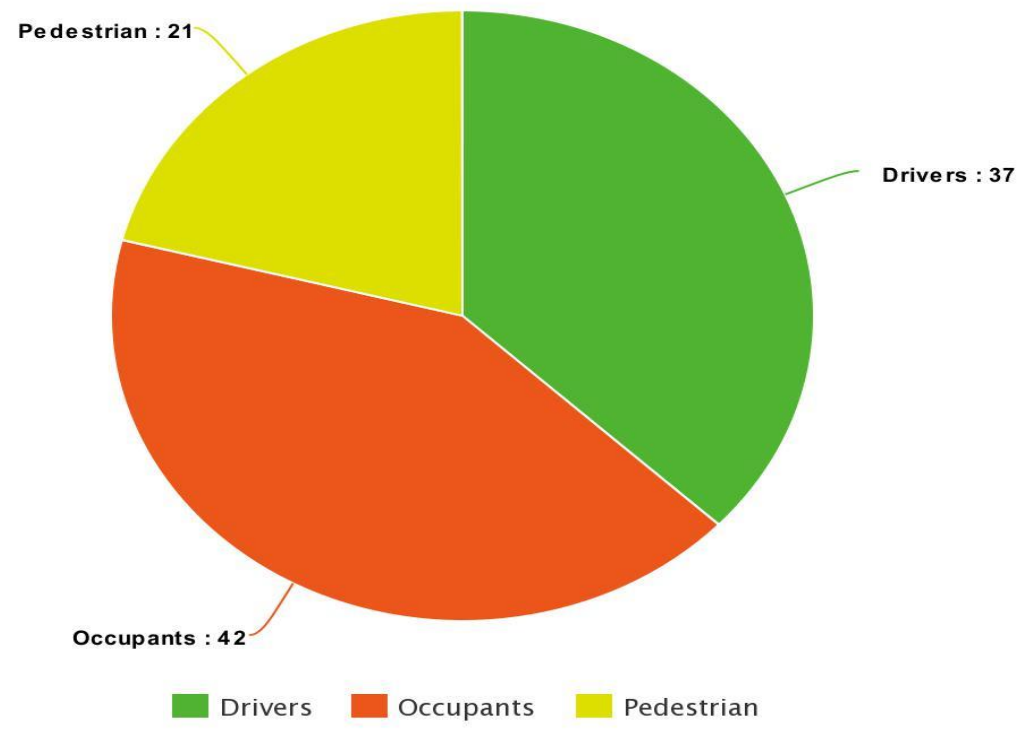

Figure7: Deaths as related to the positions of RTAs victims

\section{CONCLUSION}

This study has shown the data recorded for road traffic accidents in 2011 for the largest hospital in Benghazi. We conclude that even with the event of war at that year and distribution of different types of weapons still deaths from RTA has increased by $33 \%$ when compared with other traumatic deaths as in deaths due to gunshot $29 \%$.

\section{REFERENCES}

[1] Peden MM, Scurfield R, Sleet D, Mohan D, Hyder AA, Jarawan E, ET al.2004.World report on road traffic injury prevention. Geneva: WHO.

[2] World Health Organization Global Status Report on Road Safety 2013; Time for action.
Availableonline:http://www.un.org/ar/roadsafet y/pdf/roadsafetyreport. pdf

[3] Murray CJL, Lopez AD.1996. The global burden of disease and injury series. Volume I. A comprehensive assessment of mortality and disability from diseases, injuries, and risk factors in 1990 and projected to 2020. Geneva: WHO.

[4] Mortality statistics and road traffic accidents in the UK (NHS, 2011).

[5] Peden M, Sminkey L (2004) World Health Organization dedicates. World Health Day to road safety. Inj Prev 10: 67.

[6] (2003) Traffic fatalities and economic growth April 2003. The World Bank.

[7] WHO (2015) violence and injury prevention. Global status report on road safety 2015 . 
[8] Road traffic accidents statistics for the year 2009. Department of Traffic and Licenses, Libya. 179 p. [In Arabic] 2009.
[9] Road traffic accidents statistics for the year 2008. Department of Traffic and Licenses, Libya.165p. [InArabic] 2008

Citation: Samir Elmrghni, Mahmud Kaddura. Road Traffic Accident Deaths in Benghazi during (2011), ARC Journal of Forensic Science. 2019 4(1):35-39. http://dx.doi.org/10.20431/2456-0049. 0401005

Copyright: (c) 2019 Authors. This is an open-access article distributed under the terms of the Creative Commons Attribution License, which permits unrestricted use, distribution, and reproduction in any medium, provided the original author and source are credited. 